\title{
A formação profissional em Secretariado Executivo e o ensino de Inglês para negócios
}

The professional Executive Secretariat training and the business English teaching

\author{
Maura Bernardon ${ }^{1(D)}$ \\ ${ }^{1}$ Universidade Estadual do Oeste do Paraná (Unioeste), Brasil, Doutora em Letras (UFBA), professora de língua inglesa no \\ curso de Secretariado Executivo Trilíngue (Unioeste), e-mail: maurabernardon@gmail.com
}

\begin{abstract}
RESUMO
Este estudo descreveu uma unidade do livro didático de inglês para negócios, nível elementar Business Result, Student's Book (GRANT; HUGHES; REBECCA, 2012). Inicialmente, apresentou-se o perfil profissional do Secretariado Executivo (SE) no contexto atual e as habilidades necessárias para a sua formação profissional, destacando-se o uso da linguagem. Na sequência, tomaram-se como referência teórica as perspectivas sobre gêneros da linguagem e gramática do design visual (GDV). Teve-se como objetivo principal descrever ações e representações sociais, instituídas por meio de gêneros da linguagem, e seu vínculo com o cotidiano dos profissionais de SE. A metodologia foi de base interpretativista e descritiva, seguindo os padrões da pesquisa qualitativa. A análise mostrou que as atividades se reportam à área da comunicação, ações ecologicamente corretas, tecnologias avançadas e o uso de documentos administrativos e pessoais. A partir do estudo sobre a formação profissional dos assistentes administrativos, ou SE, gêneros da linguagem e GDV constatou-se que as atividades analisadas fazem parte das rotinas administrativas das organizações em geral. Da mesma forma, o ensino de línguas para negócios procura reproduzir ações pedagógicas voltadas para esse contexto, sendo uma possibilidade para a formação profissional do SE.
\end{abstract}

Palavras-chave: Inglês; Formação; Secretariado.

\begin{abstract}
This study described one unit in the Business English textbook, elementary level, Business Result, Student's Book (GRANT; HUGHES; REBECCA, 2012). Initially, the Executive Secretariat (ES) professional profile was presented, as well as the skills for its professional training, highlighting the use of language. Then, the perspectives about language genres and visual design grammar (VDG) were approached. The main objective was to describe social actions and representations, instituted by means of language genres, and their connection to ES professionals. The methodology was interpretive and descriptive, following the qualitative patterns. The analysis showed that the activities refer to communication studies, ecolocally correct actions, advanced technologies and the use of administrative and personal documents. Based on the studies of future challenges for the executive and administrative assistants, or ES, language genders, and GDV, it was possible to conclude that the activities are part of the administrative routines of organizations in general. Finally, the teaching of languages for business seeks to reproduce specific pedagogical actions for that context and it is a possibility for the ES professional training.
\end{abstract}

Keywords: Training; English; Secretariat. 


\section{INTRODUÇÃO}

Esta investigação retoma estudos anteriores de Cantarotti (2018), Bernardon, Alda e Hahn $(2017 ; 2019)$ que tratam da carência de material didático de língua inglesa para cursos de SE. Como forma de compensação para essa ausência, têm-se utilizado livros publicados por editoras internacionais, reconhecidas mundialmente pela sua qualidade, dentre elas: Macmillan, Oxford e Pearson.

O estudo de Bernardon, Alda e Hahn (2017) sobre a análise das doze unidades do livro Business Result, Student's Book (GRANT; HUGHES; REBECCA, 2012), nível elementar, mostrou que a maior parte dos temas se refere ao campo dos negócios em geral, entretanto dois deles chamaram a atenção pela proximidade com as práticas secretariais (Comunicação e Viagens) e que fazem parte da grade curricular de um curso de SE (PPP, 2017). Igualmente, considerando o estudo de Mesquita, Oliveira e Sequeira (2019), em que a atuação profissional do SE não se resume a atividades operacionais, concluiu-se que o livro contribui para suprir a falta de materiais didáticos específicos para o SE, já que esse profissional deve ser preparado para desempenhar multitarefas. Como sugestão para estudos futuros, indicava-se investigar as atividades didáticas propostas no livro, comparando-as com suas práticas profissionais, o que será realizado a seguir.

Assim sendo, duas atividades que mais aproximaram-se das rotinas profissionais do SE foram escolhidas, verificando-se os tipos de atividades linguísticas e gêneros escolhidos. Como questionamentos principais determinou-se: a) quais habilidades e gêneros da linguagem esses livros abordam e b) se estariam em consonância com os desafios que a $4^{\circ}$ Revolução Industrial e os impactos da digitalização para os profissionais da área secretarial, especialmente no que se refere ao uso de gêneros da linguagem, considerados essenciais para a qualificação profissional do SE na atualidade.

Para tanto, buscou-se a fundamentação teórica nos estudos sobre gêneros discursivos/textuais, que recebem a denominação mais recente de gêneros da linguagem. Segundo Paiva (2019),

Gêneros da linguagem é um termo guarda-chuva que inclui texto e discurso e outros modos semióticos. Ao optar por "gêneros da linguagem", não excluo gêneros textuais", "gêneros do discurso" ou "gêneros discursivos", ao contrário, os incluo no guarda-chuva e acolho gêneros não verbais, que também são ações de linguagem. Ao

Revista Expectativa, Toledo/PR, v.20, n. 1, p. 1-16, jan./mar., 2021. 
fazer essa opção, apoio-me em uma visão de linguagem na perspectiva da complexidade (PAIVA, 2019, p.67). ${ }^{1}$

De acordo com estudos sobre tipos de pesquisa, esta investigação caracterizou-se como qualitativa, tomando-se por base o corpus e os procedimentos metodológicos para a descrição dos gêneros da linguagem (verbal e não-verbal). A seguir, descreve-se a fundamentação teórica que embasou a temática abordada, os procedimentos metodológicos adotados, os resultados encontrados e a conclusão da investigação.

\section{REFERENCIAL TEÓRICO}

\subsection{OS NÍVEIS DE PROFISSIONAIS NA ÁREA SECRETARIAL}

A busca pelo compasso entre a formação acadêmica e a prática profissional tem sido objeto permanente de preocupação por parte dos cursos de graduação, que envolvem a avaliação das grades curriculares e projetos políticos pedagógicos de tempos em tempos. Ao retomar três estudos anteriores sobre o perfil profissional do SE, demandado pelo mundo corporativo tanto nacional como estrangeiro, mais recentemente, destacam-se as habilidades que envolvem a tecnologia, o domínio de línguas materna, estrangeiras e as habilidades interpessoais (ALMEIDA; BORINI; SOUZA, 2018; MESQUITA; OLIVEIRA; SEQUEIRA, 2019).

Segundo Leal e Moraes (2017), em estudo sobre as competências necessárias para a gestão da internacionalização das IES brasileiras, em tese, concluíram que, com base em uma tabela conceitual comparativa das competências atribuídas ao SE, esse profissional apresenta competências que podem contribuir para a gestão da internacionalização em instituições brasileiras. Segundo os autores, "Trata-se de um profissional que tem se esforçado para ajustar seu perfil às necessidades organizacionais. Com isso, migrou de um campo operacional/mecanicista para um campo tático/estratégico.” (LEAL; MORAES, 2017, p.159).

Da mesma forma, Almeida, Borini e Souza (2018) compararam competências necessárias para a atuação no mercado de trabalho em organizações nacionais e internacionais, relacionando o conhecimento técnico às atividades que envolvem redação de documentos e

\footnotetext{
${ }^{1}$ A perspectiva da complexidade vem sendo integrada aos estudos linguísticos com base em Larsen-Freeman e Cameron (2008) e dialoga com os estudos de Bakhtin e seus principais conceitos.
}

Revista Expectativa, Toledo/PR, v.20, n. 1, p. 1-16, jan./mar., 2021. 
atendimento telefônico, por exemplo. Já no comportamental, outras competências serão exigidas, dentre elas: relacionamento com o cliente, trabalho em equipe, gestão do tempo, criatividade e negociação.

Na sequência, Almeida, Borini e Souza (2018, p. 10) afirmam que "Em que pese à relevância de tais resultados discutidos até o momento, as competências necessárias ao profissional de secretariado abrangeriam não só a esfera técnica, mas também a comportamental." Para complementar essas reflexões, Almeida, Borini e Souza (2018, p. 3) apontam que as empresas desejam um perfil "que contemple os dois níveis de aprendizado teórico-prático e a segurança na aplicação de conhecimentos acadêmico-profissionais em secretariado."

No âmbito internacional, o estudo de Mesquita, Oliveira e Siqueira (2019) também aponta dois níveis de profissionais na área secretarial: um voltado às tarefas operacionais e o segundo à resolução de tarefas mais complexas, remetendo especificamente à área da comunicação e à solução de problemas, negociações e suporte às chefias. O nível básico seria denominado "Assistente Administrativo", envolvendo tarefas administrativas, tais como o uso do computador ou atividades mais operacionais Já, o segundo, reconhecido como "Assistente Executivo ou Secretário(a) Executivo(a)”, exige ações interpessoais, fluência em línguas estrangeiras para a compreensão e negociação com parceiros de culturas estrangeiras, entre outras. Ademais, as operações diárias desse nível requerem habilidades adicionais, como por exemplo, as orientações de serviços e pessoas, operações cognitiva-intelectuais e que os autores consideram que permanecerão, independentemente dos avanços tecnológicos (MESQUITA; OLIVEIRA; SEQUEIRA, 2019, tradução nossa).

Essa referência de requisitos e práticas sociais, tanto no campo cognitivo como operacional, permite aos linguistas apontarem diferentes gêneros da linguagem (verbal e nãoverbal), inclusive de letramentos digitais empregados no contexto profissional do SE. Igualmente, a partir de domínios de conhecimento em que as posições de trabalho que o SE pode atuar, citadas acima, as pesquisas linguísticas têm a contribuir por meio do ensino de línguas estrangeiras e da análise do discurso organizacional, isto é, investigando as formas de interações institucionais e determinando relações de poder, tal como nas entrevistas de emprego (VAN DIJK, 2008). Da mesma forma, são os estudos desenvolvidos com base em gêneros textuais e uso da linguagem em diferentes práticas sociais de atuação do SE que se complementam para o entendimento da linguagem humana, sistema tão complexo.

Revista Expectativa, Toledo/PR, v.20, n. 1, p. 1-16, jan./mar., 2021. 
Esse levantamento sobre os níveis de profissionais na área secretarial, vem também corroborar para a análise das atividades propostas no ensino de inglês para negócios. A formação em língua estrangeira está acompanhando as mudanças e exigências do mercado? Como produzir materiais didáticos que abordem a compreensão e negociação com parceiros de culturas estrangeiras, gêneros que foquem na comunicação organizacional, operações diárias e relações interpessoais que abordam o SE, questionamentos esses que fazem parte da prática de sala de aula de língua inglesa.

\subsection{TEORIA DOS GÊNEROS DA LINGUAGEM E MULTIMODALIDADE}

Nesta seção, saliento as influências dos estudos sobre gêneros na perspectiva dialógica do discurso, de Bakhtin (2000). Segundo essa perspectiva, os aspectos sociais e históricos em que os sujeitos estão inseridos e o contexto de produção do enunciado facilitam o entendimento da constituição da língua, ou seja, em como a língua se organiza, pois a análise dos gêneros se dá também no próprio texto, observando-se os elementos linguísticos e estruturais que o constituem, ou seja, a sua composição interna.

Nos estudos sobre gêneros numa concepção dialógica da linguagem, a língua é vista como polifônica e incorpora o diálogo de outras vozes às do enunciador Bakhtin (2000). E, apesar das diferenças formais entre os textos, ou enunciados, o aspecto linguístico é tomado como denominador comum para a investigação. Nos últimos anos, propostas voltadas para o ensino dos gêneros da linguagem estão tentando sair de uma metodologia de ensino que somente apresenta os gêneros aos estudantes e que trabalha apenas com a análise linguística dos textos. Elas pretendem também considerar as formas comunicativas numa determinada formação social (MARCUSCHI, 2008; BRONCKART, 2009). Desta forma, o conceito de gênero com base nos estudos bakhtinianos se torna um pressuposto teórico para a análise da forma e da função social dos discursos, assim como uma ferramenta no ensino e aprendizagem de língua.

De Bakhtin (2000) ficaram os subsídios teóricos de ordem macroanalíticas eas noções mais amplas, tais como a categorização em gêneros primários (diálogos orais e escritos cotidianos), secundários (a tese acadêmica e o romance que absorvem e transmutam os gêneros primários e são mais elaborados) e as categorias de análise do gênero como o tema, a composição e o estilo. Ele ressalta que a natureza do enunciado precisa ser investigada para que

Revista Expectativa, Toledo/PR, v.20, n. 1, p. 1-16, jan./mar., 2021. 
possamos conhecer a formação histórica dos gêneros, a inter-relação entre gêneros primários e secundários e a correlação entre língua, ideologia e visões do mundo.

Ainda nesse sentido, nos estudos da linguagem destaca-se a produção escrita, mas a oralidade e os aspectos não linguísticos (imagens e sons) também são levados em conta, caracterizando-se o texto como multimodal. Formas discursivas inovadoras surgem devido às novas tecnologias midiáticas e causam uma certa redefinição da linguagem em uso, principalmente, causando um certo hibridismo entre a oralidade e a escrita. Portanto, pode-se afirmar que um gênero da linguagem veicula uma mensagem, linguística ou imagética, organizada, que tende a produzir um efeito de coerência sobre o leitor e que sofre influência do contexto social em que se insere.

Os aspectos a serem considerados nos estudos dos gêneros vão desde os padrões sociocomunicativos, as composições funcionais, os objetivos enunciativos até os estilos concretamente realizados na integração de forças históricas, sociais, institucionais e técnicas. Em outras palavras, os gêneros possuem identidade, são formas culturais e cognitivas de ação social e são entidades dinâmicas (BRONCKART, 2009). Segundo Saito (2009), há uma diversidade de dimensões da textualidade para a análise do gênero, que decorre do tipo de metodologia adotada, principalmente, devido às características dos dados empíricos coletados e das características da análise que lhes é aplicada. Assim, pode-se avaliar a composição do gênero segundo: à situação social de produção (tema, atendimento a interação estabelecida, ao contexto de produção, à circulação, à recepção, ao formato, e ao domínio da capacidade de linguagem que o gênero requer); os aspectos textuais (coesão e coerência) e norma culta (concordância, regência, conjugação verbal, pontuação, aspectos ortográficos) e à intertextualidade.

Em complementação a análise, por se tratar de um livro didático contendo imagens, emprega-se os estudos da gramática do design visual (GDV) de Kress e Van Leeuwen (2006). A multimodalidade é uma característica de livros didáticos de ensino de línguas, pois se utilizam de muitas ilustrações para contextualizar o ensino.

Nessa abordagem, os significados se enquadram em três categorias: representacional (ideacional), interativo (interpessoal) e composicional. A ideacional ou representacional, representa o mundo a nossa volta e o que somos, tais como indivíduos sociais (ideias e pensamentos), a natureza dos eventos, os participantes envolvidos e as circunstâncias; a 
segunda, a função interpessoal leva aos tipos de interações e relações sociais. A terceira função é a composicional e que está relaciona ao modo de distribuição da informação, ou ênfase entre os elementos do texto e as imagens. Assim como a linguagem possui categorias de análise, tal como as estruturas gramaticais, as imagens receberam classificações, para citar algumas: cor, ângulo e enquadramento. Desta forma, a GDV consegue fazer com que as imagens e essas metafunções possam ser interpretadas e compreendidas, criando uma ponte entre o seu criador e o leitor, descortinando diferentes aspectos do mundo de forma sistemática (BERNARDON, 2005; KRESS; VAN LEEUWEN, 2006; SALBEGO; HEBERLE; BALEN, 2015).

Desta forma, a análise de diferentes gêneros, inclusive os imagéticos, revela as funções e os objetivos das ações cotidianas contemporâneas e, portanto, faz-se necessário abordar e interpretar o que está sendo representado por meio das imagens. Para tanto, os estudos dos meios visuais vêm sendo explorados em revistas femininas, nas revistas do meio corporativo, principalmente em propagandas, nas charges, livros didáticos e, mais recentemente, em jogos virtuais (BERNARDON, 2005; HEBERLE, 2019; SALBEGO; HEBERLE; BALEN, 2015;).

A partir desse entendimento, as atividades do livro escolhido para análise representam ações realizadas em gêneros inseridos no contexto dos negócios e também do cotidiano do SE.

\section{PROCEDIMENTOS METODOLÓGICOS}

Este estudo desenvolveu-se no contexto de formação acadêmica, nível de graduação em SE, por meio da descrição dos gêneros da linguagem e da gramática do design visual no livro Business Result-Student's Book, de Grant, Hughes, Rebecca (2012), série didática que é utilizada como bibliografia para o ensino de inglês para negócios. A partir do questionamento de pesquisa, inicialmente, elencaram -se algumas das habilidades e práticas de trabalho consideradas necessárias atualmente para o desempenho das principais funções desse profissional. Concomitantemente, levou-se em consideração as teorias linguísticas que entendem que a linguagem são formas de ação social, realizadas nos mais diferentes domínios do conhecimento, moldadas por eles e suas diferentes estruturas, tais como as organizações públicas e privadas. Para tanto, optou-se pelos estudos sobre gêneros da linguagem e da gramática do design visual, uma vez que o livro didático se constitui não somente da linguagem escrita, mas também de imagens.

Revista Expectativa, Toledo/PR, v.20, n. 1, p. 1-16, jan./mar., 2021. 
Pelo fato de se ter como dados para a análise um material em forma de texto impresso, sem objetivos de levantamento numérico, e tão somente de interpretação e descrição, variáveis ou manipulação por parte do pesquisador, trata-se de pesquisa de natureza qualitativa (DENZIN; LINCOLN, 2006). Quanto aos métodos de investigação é "um estudo de caso, apoiado no método exploratório-descritivo" (GIL, 2008, p. 28). A pesquisa exploratória se enquadra neste estudo pela não rigidez no planejamento, envolver um levantamento documental e ser um estudo inicial. O corpus se constituiu de duas atividades da unidade cinco, parte do conteúdo programático, livro do aluno, Business Result (GRANT; HUGHES; REBECCA, 2012), editora Oxford, nível elementar.

No que se refere ao tipo descritivo, as atividades propostas pelos autores foram interpretadas seguindo Bakhtin (2000), Marchuschi (2008), Bronkart (2009) e da gramática do design visual proposta por Kress e Van Leeuwen (2006). Conforme justificativa de que a linguagem verbal e não-verbal, realizadas por meio de gêneros, se complementam para construir os discursos, na sequência apresentam-se as interpretações e descrições preliminares sobre os gêneros e imagens presentes nas atividades, juntamente com os resultados e discussões

\section{APRESENTAÇÃO E ANÁLISE DOS RESULTADOS}

Nesta seção, apresenta-se uma amostra de como as atividades didáticas de inglês para negócios relacionam-se com as temáticas e as práticas do cotidiano das organizações e na formação acadêmica dos que atuam na área administrativa.

\subsection{ANÁLISE DAS ATIVIDADES NA UNIDADE “COMMUNICATION" - BUSINESS RESULT STUDENT BOOK -ELEMENTARY (GRANT; HUGHES; REBECCA, 2012)}

De acordo com a análise realizada nas atividades propostas na unidade “Communication”, observa-se que o objetivo é trazer para a sala de aula a discussão sobre soluções de problemas quanto às práticas ecologicamente corretas dentro das empresas, o uso de ferramentas digitais e os tipos de documentos e correspondência os alunos podem vir a utilizar no seu cotidiano profissional, o que pode ser visualizado também nas figuras apresentadas ao longo da seção.

Revista Expectativa, Toledo/PR, v.20, n. 1, p. 1-16, jan./mar., 2021. 
Figura1 - Unidade 5 Communication

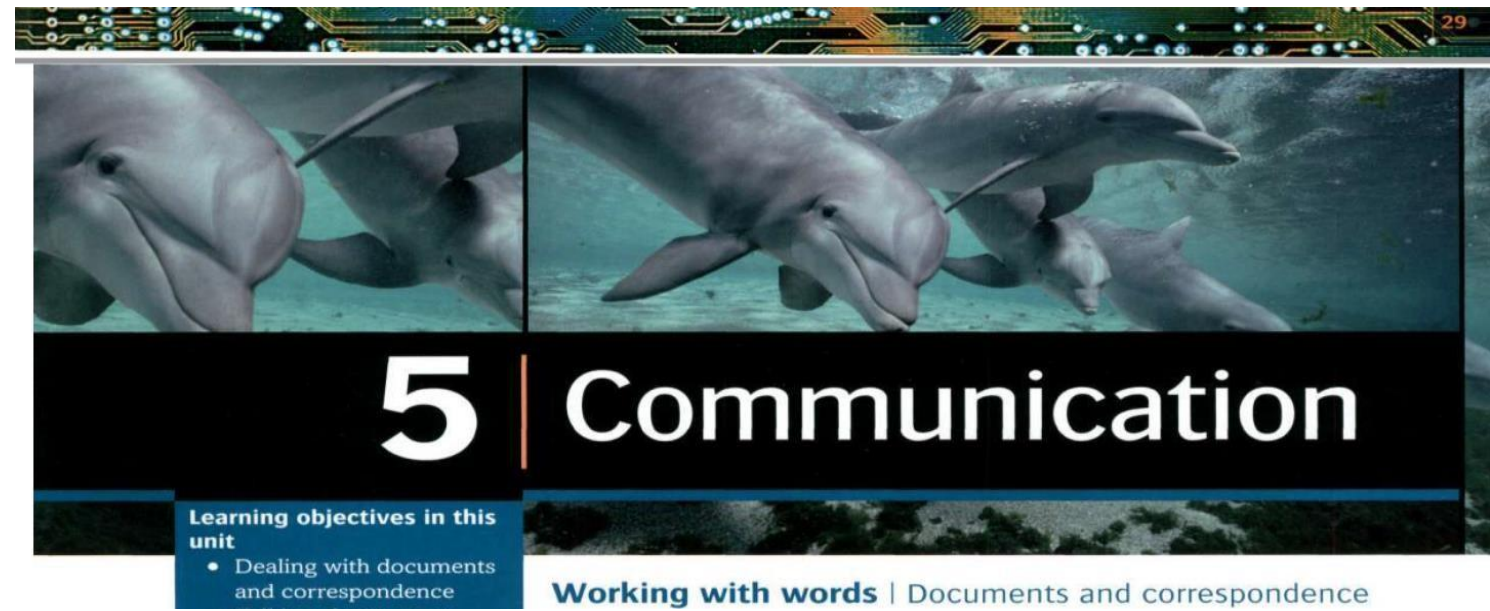

Fonte: Business Result Student Book-Elementary (GRANT; HUGHES; REBECCA, 2012, p. 30)

Na página inicial da unidade 5, encontra-se a imagem de golfinhos, justamente para remeter o leitor ao título e o tema desta unidade. Nesta captura, as três metafunções se definem em: a) representacional, o mundo dos golfinhos; b) como eles interagem entre si, a interpessoal; e c) composicional na ênfase dada ao título "Communication" e na posição transacional, isto é, de interação com o leitor. Assim, pode-se afirmar que animais representam um tipo de associação, pois mantêm entre si relações próximas e colaborativas, comunicando-se por meio de estalos e assobios, indicando suas posições para os demais e na busca por alimento. Também interagem muito bem com os humanos e estudos recentes mostram que tendem a imitar sons humanos e repetir palavras (CIÊNCIAS RESUMOS, 2019).

Nesta página, chama a atenção o subtítulo da unidade que trata de documentos e correspondências, palavras que indicam o assunto a ser tratado logo a seguir. No primeiro exercício, solicita-se a leitura de um texto sobre a redução do uso de papel e como melhorar a comunicação da empresa. O exemplo de apoio dado para justificar a escolha do assunto é uma empresa japonesa, reconhecida pelas suas práticas ecológicas e na criação de sistemas de tecnologia da informação e da comunicação (TIC), como mostra o subtítulo em cores vermelha e preto, com o intuito de chamar a atenção. No lado esquerdo, localizam-se duas perguntas, que servem para interagir e trazer o contexto do aluno para a discussão sobre tipos e tempo gasto com as correspondências. No modo verbal (perguntas) fica evidente a metafunção “interacional”, tão presente em livros de ensino de línguas estrangeiras. Segundo a teoria da análise de imagens de Kress e Van Leuwen (2006), o que está na parte superior, no lado

Revista Expectativa, Toledo/PR, v.20, n. 1, p. 1-16, jan./mar., 2021. 
esquerdo é o dado, ou seja, aquilo que o leitor já reconhece, isto é, subtende-se que o aluno já tenha conhecimento de correspondências e o tempo que ele gasta para isso. Já, à direita da página coloca-se um dado novo, representado pela figura de uma mulher, usando um uniforme de enfermeira olhando para um tablet (uma ação reacional: não-transacional, sem interação com o leitor) e que faz relação com o profissional da área da saúde mencionado no texto. Esta figura se contrapõe a imagem no canto inferior, também à direita, com uma máquina impressora de papel, para mostrar a importância do uso de ferramentas de trabalho mais avançadas tecnologicamente. Finalizando a atividade, há uma pergunta sobre se a empresa do leitor utiliza grandes (lots) quantidades de papel, retomando o tema da atividade, como pode ser observado na Figura 2.

Figura 2 - Atividade 1 - Working with words: Documents and correspondence

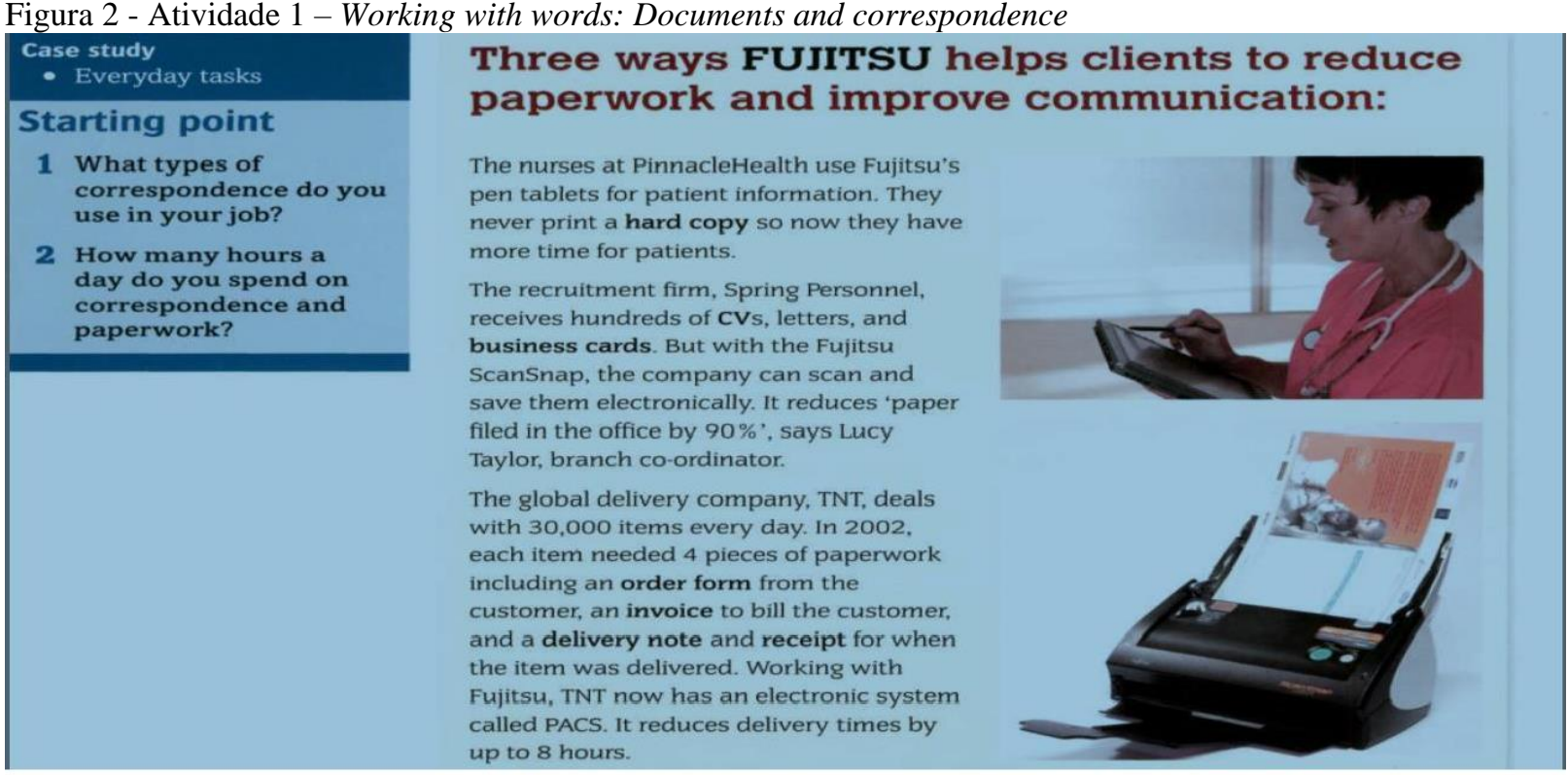

2 Does your company produce lots of paperwork? How does it reduce it?

Fonte: Business Result - Elementary (GRANT; HUGHES; REBECCA, 2012, p. 30)

Na sequência, os exercícios trabalham o vocabulário de vários gêneros da linguagem, característicos do domínio organizacional, tais como: $C V s$, (currículo vitae) Business cards, (cartões de negócios), order form, (formulários de pedidos), invoice, (faturas), delivery note, (notas de entrega) e receipt (recibos). (Figura 2). Na atividade seguinte, duas perguntas fazem novamente a interlocução com o leitor, sobre os documentos citados anteriormente e se esses são utilizados no trabalho.

Revista Expectativa, Toledo/PR, v.20, n. 1, p. 1-16, jan./mar., 2021. 
$\mathrm{Na}$ atividade 05, utiliza-se um exercício de áudio, retomando o conteúdo sobre documentos e correspondências, por meio da habilidade de compreensão oral, como mostra a Figura 3.

Figura 3 - Atividade 2 - Does your company produce lots of paperwork? How does it reduce it?

3 What documents do you need in these situations? Match the words in bold in 1.

1 You want to apply for a job.

2 You want to place an order.

3 You make a payment.

4 You meet someone for the first time.

5 You send a customer a list of the items they ordered and the total price.

6 The delivery company brings you 20 boxes.

7 Your boss wants to read your report. You need to print it.

4 Which of the documents in 3 do you use at work? What other types of documents do you deal with at work?

$527 \triangleright$ Listen to a telephone conversation.

1 What is the problem?

2 What types of documents or correspondence do they mention?

Fonte: Business Result - Elementary, (GRANT; HUGHES; REBECCA, 2012, p. 31)

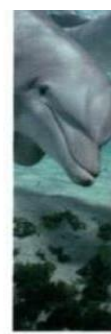

$\frac{\text { 동 }}{\text { जा }}$

No exercício 6, Figura 4, há uma atividade de vocabulário seguida de pequenas imagens para serem relacionadas com as palavras (que representam o Ideal e as imagens o Real) de partes de um computador. Em termos de gramática visual, os participantes também podem ser representados por objetos, nesta figura as partes do computador Actor. Os significados estão relacionados com a distribuição da informação ou ênfase entre elementos do texto e da imagem. As setas, ou vetores, servem para indicar ao leitor (segundo participante), ou também conhecido como Goal, onde deve-se realizar cada processo de ação. Esta atividade pode ser relacionada às tarefas operacionais, tal como redação de documentos e atendimento telefônico, mencionadas em Almeida, Borini e Souza (2018).

Revista Expectativa, Toledo/PR, v.20, n. 1, p. 1-16, jan./mar., 2021. 
Figura 4. Atividade 6 -Listening

$627 \triangleright$ Listen again and make verb + noun combinations from A and B. Then match the words to the pictures.

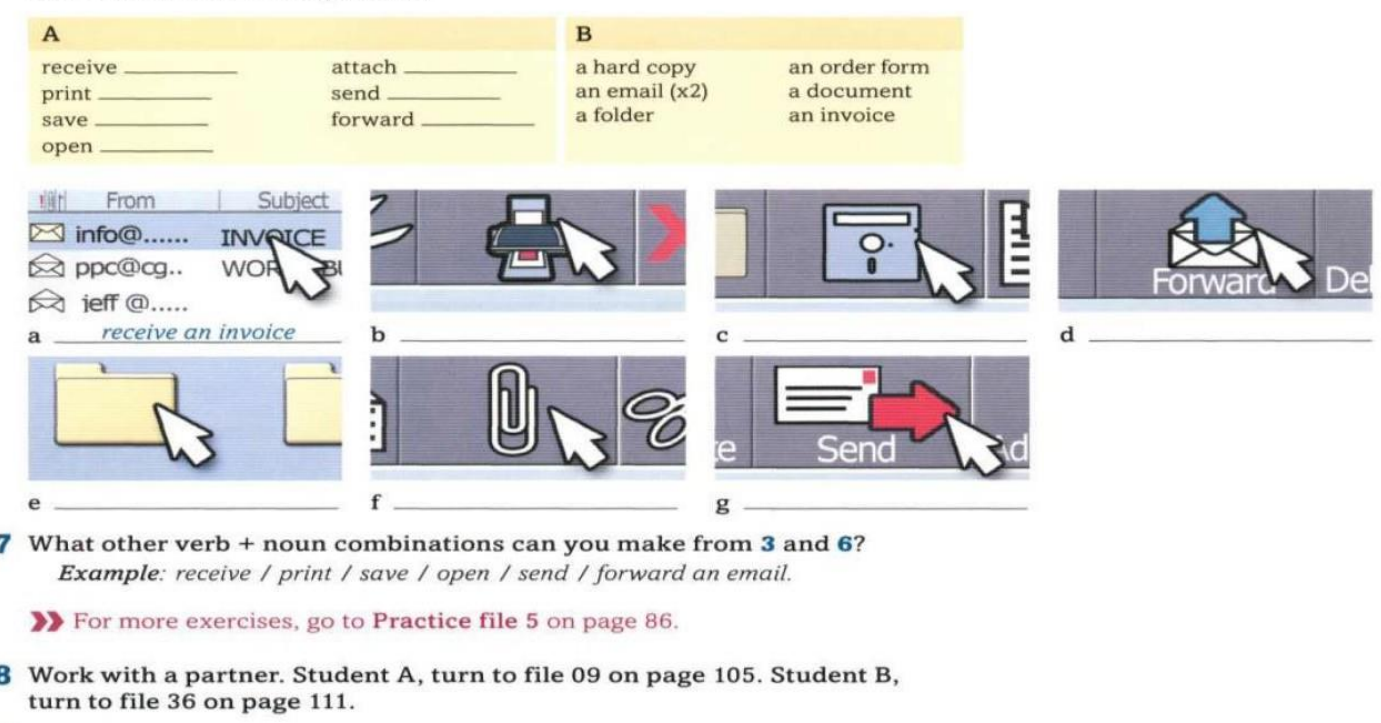

Fonte: Business Result - Elementary (GRANT; HUGHES; REBECCA, 2012. p. 31)

Nesta breve análise, observam-se padrões de uso intercalados entre imagens e textos, comandos e perguntas. Na primeira imagem, os golfinhos foram utilizados como forma de representação sobre o conceito de comunicação, indicando sobre o que trataria a unidade. A imagem serviu para atrair o leitor, já que esses animais são reconhecidos como comunicativos. No exercício 1, as imagens intercalam-se como texto, revelando ações tanto humanas como de máquinas e introduzindo a temática da necessidade da substituição de artefatos tecnológicos mais ecologicamente corretos. Predomina a metafunção interpessoal entre participantes, sejam entre o autor e o leitor, ou entre objetos e o leitor, como no caso do exercício 6.

Chama a atenção como o autor utiliza a linguagem verbal, por meio de perguntas, para se referir ao contexto de trabalho e solicita comandos e ações que envolvem conceitos e atividades da área administrativa. Cita gêneros da modalidade escrita, porém sem identificálos, supondo que o leitor já os conheça. A análise das imagens utilizadas na unidade comprova as intenções do autor, ou seja, servem para auxiliar o aluno a reconhecer e interagir com o seu contexto de atuação e facilitar o aprendizado do idioma, principalmente em funções operacionais e soluções de problemas.

\section{CONSIDERAÇÕES FINAIS}

Revista Expectativa, Toledo/PR, v.20, n. 1, p. 1-16, jan./mar., 2021. 
Ao retomar estudos anteriores sobre o perfil profissional do SE, demandado pelo mundo corporativo, destacam-se as habilidades que envolvem a comunicação, a tecnologia, o domínio de línguas materna e estrangeiras, assim como as habilidades interpessoais. Em relação à parte da linguagem, destacam-se os letramentos digitais, linguagem verbal, visual e gêneros textuais.

Especialmente, quanto ao profissional de SE, o artigo de Mesquita, Oliveira e Sequeira (2019) mostrou as habilidades e capacidades para o exercício da profissão secretarial, atribuindo dois níveis de profissionais e como essas categorias devem se preparar para $4^{\circ}$ Revolução Industrial. Os estudos de Almeida, Borini e Souza (2018) confirmam que o perfil desejado pelas empresas deve contemplar tanto o aprendizado teórico-prático como a segura aplicação desses conhecimentos. E, complementando, Leal e Moraes (2017) destacaram as competências atribuídas ao SE e o avanço do perfil profissional de um campo operacional/mecanicista para um campo tático/estratégico.

Esse cenário serviu para avaliar se o livro Business Result, de Grant, Hughes e Rebecca (2012), nível elementar, propõe atividades voltadas para a prática profissional dessa categoria. As atividades propostas voltaram-se às tarefas operacionais, mas também à resolução de tarefas mais complexas, remetendo especificamente à área da comunicação e à solução de problemas quanto às práticas ecologicamente corretas dentro das organizações.

Por tratar-se de um livro de ensino de idiomas, nível elementar, encontrou-se tarefas de leitura de pequenos textos, ensino de vocabulário específico sobre o uso de documentos e soluções de problemas. As perguntas, na sua maioria, servem para interagir com o aluno, de forma informal (com o uso do pronome you), direcionando-o para o seu contexto de trabalho. Entretanto, não fica claro se o aluno terá que respondê-las na língua alvo. Livros como esse têm como fim o ensino de inglês para estrangeiros, considerando os diferentes níveis de conhecimento do idioma e tendo como fundo os variados tipos de situações dentro e fora das empresas.

Neste breve estudo, apresentou-se o termo "gêneros da linguagem", permitindo a compreensão de como a linguagem compõe-se de práticas sociais específicas e que estão em constante mudança. As categorias de análise da gramática do design visual serviram para constatar que as imagens utilizadas pelos autores contribuíram para o ensino do vocabulário e contextualização do tema proposto. Do mesmo modo, observou-se a preocupação com o uso de 
ferramentas tecnológicas e soluções de problemas na comunicação, temáticas que fazem parte das organizações de negócios e do cotidiano do profissional do SE. Entretanto, as atividades analisadas oferecem uma visão geral do contexto de trabalho, sem mencionar especificamente o SE.

O uso da tecnologia confere às práticas sociais novas e diversas configurações, e os livros didáticos precisam acompanhar esse ritmo, atualizando-se para dar conta das multissemioses. Os gêneros da linguagem contemporâneos tendem a ser mais imagéticos com uma linguagem mais concisa e fragmentada, que permita uma compreensão mais rápida e com um alcance globalizado. A escrita, em qualquer língua, sofreu e vem sofrendo mudanças e os textos estão mais fluidos com as virtualidades mutantes das novas mídias (BARTON; LEE, 2015). Nessa investigação inicial, observou-se que as ferramentas digitais não podem mais ficar de fora do currículo. E, na medida em que as novas tecnologias da informação passam a fazer parte da educação, novos paradigmas de abordagens multimodais devem ser desenvolvidos. Novas habilidades de autorias multimidiáticas, análise crítica e estratégias de exploração multimodais já fazem parte dos estudos linguísticos, tal como o ensino por meio de jogos virtuais e outros sistemas tecnológicos. As atividades de escrita ainda predominam na maioria das salas de aula, porém já não é mais novidade as abordagens interativas estarem substituindo as curriculares (LEMKE, 2010).

\section{REFERÊNCIAS}

ALMEIDA, W. A. G.; BORINI, F. M.; SOUZA, E. C. P. Competências comportamentais dos profissionais de secretariado: o impacto da atuação internacional da empresa. Revista Gestão e Secretariado, v. 9, n. 1, 2018.

BARTON, D.; LEE C. Linguagem online: textos e práticas digitais. 1.ed. São Paulo: Parábola Editorial, 2015.

BAKHTIN, M. Estética da criação verbal. São Paulo: Martins Fontes, 2000.

BERNARDON, M.; ALDA, G. C. B.; HAHN, M. C. Inglês para negócios no Secretariado Executivo: os temas no livro didático "Business Result - Elementary". In: CONGRESSO BRASILEIRO DE LINGUÍSTICA APLICADA, 12., 2019, Vitória. Anais [...]. Vitória, 2019.

BERNARDON. M; ALDA. G.C.B.; HAHN, M.C. O livro didático Business Result Elementary e o ensino de língua para negócios no Secretariado Executivo (Se) da Unioeste. 
In: ENCONTRO REGIONAL, 20., SEMANA ACADÊMICA DE SECRETARIADO EXECUTIVO, 31., 2018, Toledo. Anais [...]. Toledo: Unioeste, 2018.

BERNARDON, M. Women in business context represented in the magazines Secretária Executiva and Mulher Executiva: a lexicogrammatical and visual analysis. 2005. 116 p. Dissertação (Mestrado em Letras/Inglês e Literatura) - Centro de Comunicação e Expressão, Universidade Federal de Santa Catarina, Florianópolis, 2005.

BRONCKART, J. P. Instruções de linguagem, textos e discursos: por um interacionismo sociodiscursivo. São Paulo: EDUC, 2009.

CANTAROTTI, A.; PINTO, T. P. Inglês para fins específicos e o ensino para o secretariado: data driven learning e tradução. The ESPecialist, v. 39, n. 1, jan./jul., 2018.

CIÊNCIAS RESUMOS. Golfinhos: características e curiosidades. 2019. Disponível em: https://www.cienciasresumos.com.br/animais/golfinhos- características-e-curiosidades. Acesso em: 21 jul. 2019.

DENZIN, N.; LINCOLN, Y.S. O planejamento da pesquisa qualitativa - Teorias e abordagens. Porto Alegre: Artmed, 2006.

GIL, A. C. 2008. Métodos e técnicas de pesquisa social. 6. ed. São Paulo: Atlas.

GRANT, D.; HUGHES, J.; REBECCA T. Business English Student's Book - Elementary. Oxford: OUP, 2012.

HEBERLE, V. Linguística Aplicada, Multimodalidade e Multiletramentos. In: FINARDI, K. R. et al. Transitando e transpondo n(a)Linguística Aplicada. Vitória: Pontes, 2019. p. 5582.

KRESS, G.; VAN LEEUWEN, T. Reading images: the grammar of visual design. London/New York: Routledge, 2006.

LEAL, F. G.; MORAES, M. C. B. Perspectivas de Atuação do Secretário Executivo na Gestão da Internacionalização da Educação Superior. Revista de Gestão e Secretariado, v. 8, n. 1, p. 138-167, 2017.

LEMKE, J. L. Letramento metamidiático: transformando significados e mídias. Trabalhos em Linguística Aplicada, v. 49, n. 2, p. 455-479, 2010.

MARCUSCHI, L.A. Produção textual, análise de gêneros e compreensão. São Paulo: Parábola Editorial, 2008.

MESQUITA, A.; OLIVEIRA, L.; SEQUEIRA, A., A.; TheFuture of the Digital Workforce: Current and Future Challenges for Executive and Administrative Assistants. In: ROCHA, Á.; 
ADELI, H.; REIS, L.; COSTANZO, S. New Knowledge in Information Systems and Technologies. Galicia, Spain: Springer Nature Switzerland, 2019. p. 25-38.

PAIVA, V. L. M. Gêneros da linguagem na perspectiva da complexidade. Linguagem em (dis)curso. v.19, n.1, p. 67-85, 2019.

PPP - PROJETO POLÍTICO PEDAGÓGICO. Curso de Secretariado Executivo.

Universidade Estadual do Oeste do Paraná, Campus de Toledo, 2017. Disponível em: http://www.unioeste.br/servicos/arqvirtual/arquivos/2642016-CEPE.pdf?14:41:56. Acesso em: 25 set. 2018.

SAITO, C. L. N. Gêneros textuais e ferramentas didáticas para o ensino aprendizagem de língua portuguesa. In: NASCIMENTO, E. L. Gêneros textuais: da didática das línguas aos objetos de ensino. São Carlos: Editora Claraluz, 2009. p.195-225.

SALBEGO, N.; HEBERLE, V.; BALEN, M. G. S. S. A visual analysis of English textbooks: Multimodal scaffolded learning. Calidoscópio, v. 13, n. 1, p. 5-13, 2015.

VAN DIJK, T. A. Estruturas do discurso e estruturas do poder. In: HOFFNAGEL, K. J.; FALCONI, K. Discurso e poder. São Paulo: Contexto, 2008. 